\title{
The Procedure for Processing Images from a Low-cost UAV
}

\author{
The Case of Monitoring Landscape Changes
}

\author{
Pavel Sedlák \\ Faculty of Economics and Administration \\ University of Pardubice \\ Pardubice, the Czech Republic \\ pavel.sedlak@upce.cz \\ Jitka Komárková \\ Faculty of Economics and Administration \\ University of Pardubice \\ Pardubice, the Czech Republic \\ jitka.komarkova@upce.cz
}

\author{
Oldřich Mašín \\ Department of Crisis Management \\ Regional Authority of the Pardubice Region \\ Pardubice, the Czech Republic \\ oldrich.masin@pardubickykraj.cz \\ Jakub Jech \\ Faculty of Economics and Administration \\ University of Pardubice \\ Pardubice, the Czech Republic \\ jechisto@gmail.com
}

\begin{abstract}
Remote sensing methods have been used successfully to monitor changes in the landscape. At present, unmanned aerial vehicles (UAVs) are also increasingly used. The article shows how to use the middle-class dron, specifically DJI Phantom 3 with a built-in camera, to monitor and document changes in the vicinity of small water bodies where a part of the shore is poorly accessible or totally unavailable. The obtained data can be further processed by conventional digital image processing methods such as image classification, highlighting through spectral indexes, or even visually comparing.
\end{abstract}

Keywords - image processing; UAV; detection of changes.

\section{INTRODUCTION}

Landscape changes over time, both its horizontal and vertical structure changes. Changes can be caused by both anthropogenic and natural influences. [1] Changes in the landscape (land cover and land use) have been monitored in space and time using geoinformation technologies for a long time.

The aim of the paper is to describe the process of using images from the middle-class dron, specifically DJI Phantom 3 with a built-in camera, to monitor and document changes in the vicinity of small water bodies.

\section{PREVIOUS RESEARCHES}

Small water bodies represent a significant landscape element, and their importance is increasing today due to the increasing water shortage. Changes in the vicinity of small water bodies occur essentially constantly and need to be monitored.

\section{A. Small Water Bodies}

Water surfaces are considered to be continuous water covers on the body surface, which are relatively static in terms of flow. Different sources define small water bodies differently, and areas with an area up to 1 - 5 ha are often considered to be small water bodies. The shoreline is the physical boundary between land and water. In fact, the position of the shoreline changes continuously over time for various reasons, for example, due to coastal zone sediment, bottom water, storm, and wave effects. The work monitored the changes in the coastal zone. Parts of the coastal zone are the water area, periodically flooded areas, and coastal vegetation. The periodically flooded area is referred to as the drawdown zone. The drawdown zone is the area at the edge of a water body that is frequently exposed to air due to changes in water level. Changes in water level can be caused by evaporation or water usage in the case of reservoirs. The drawdown zone is an extremely important habitat and has many plants and animals associated with it. [2-6]

\section{B. Use UAV for Monitoring}

Remote sensing is very often used as a source of data for observation of landscape and terrain. There are many issues why this method is more reasonable than in situ observations, sampling and measurements, and land surveying. It means the costs are lower (namely in the case when bigger areas are monitored), accuracy and spatial resolution are adequate to aims of studies and finally, data measured in various parts of the electromagnetic spectrum are available. The last advantage is important for researches based on thermal imagery, various indices, etc. Satellites or aerial imagery is available for monitoring larger areas. Unmanned aerial vehicles (UAV) are increasingly used to monitor small areas, e.g. small water bodies (ponds) [7]. UAVs can provide results faster and usually with higher spatial resolution. The main part of this case study is a study of small water bodies which are monitored by a UAV.

UAVs are increasingly used in many areas of human activity. The article [8] describes the use of low-cost UAV photogrammetry for exploration for the mining of minerals in Ukraine. The eeference [9] deals with the use of drones for farm purposes. The monitoring of crop height and biomass is also addressed by [10]. The reference [11] monitors the use of UAS for the monitoring of flooded areas in the Czech Republic. Monitoring volcanoes is another way of using UAS. Monitoring of signs that prevent eruption in areas where volcanic activity occurs frequently is the key to protecting lives, livestock, and 
property [12]. UAV for glacier study in the Canadian Arctic describes [13]. The article [14] describes the mapping of the railway network using UAS photogrammetry.

\section{CASE STUdY}

The processing of images from a low-cost UAV can be divided into several basic steps:

- Goal setting

- Selection of the area of interest

- Flight planning

- Data collection

- Data processing

- Visual interpretation (or automatic processing)

- Visualization

- Interpretation.

\section{A. Area of Interest}

Define Area of interest is located near the city of Pardubice in the Czech Republic. A part of the pond with the name "Skř́ńn" was monitored (Fig. 1). The area lies northwest of Pardubice and is very rich in ponds. The area of interest is flat, lying approximately $220 \mathrm{~m}$. In the work is monitored the change of the coastal zone, which part in our study are the water surface, drawdown zone, and coastal vegetation. Coastal vegetation includes vegetation including trees, dry reeds (including dry grass) and dry trees. The territory was interested in the fragmentation of the line and accessibility. For the final analysis was used a rectangular area of approximately $1905 \mathrm{~m}^{2}$, which includes only one coastline spur.

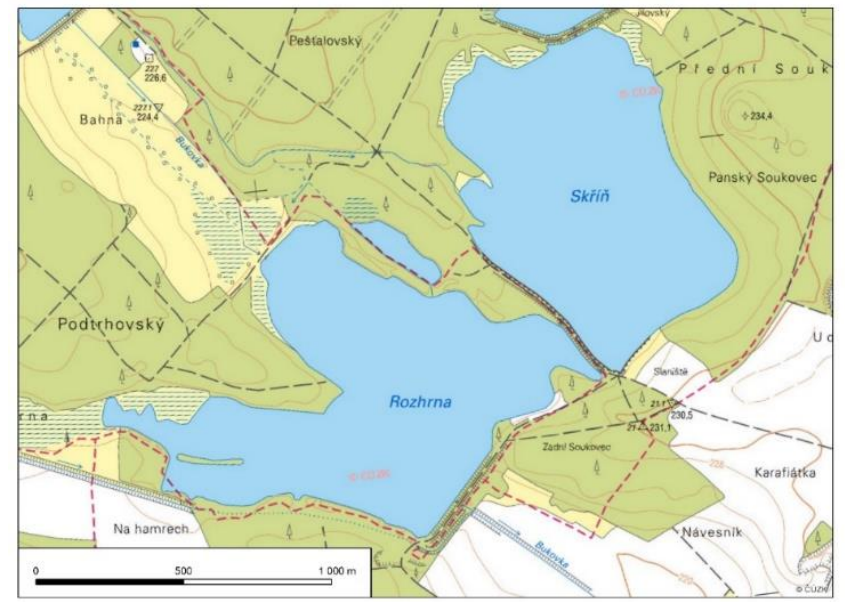

Figure 1. Map of the area of interest.

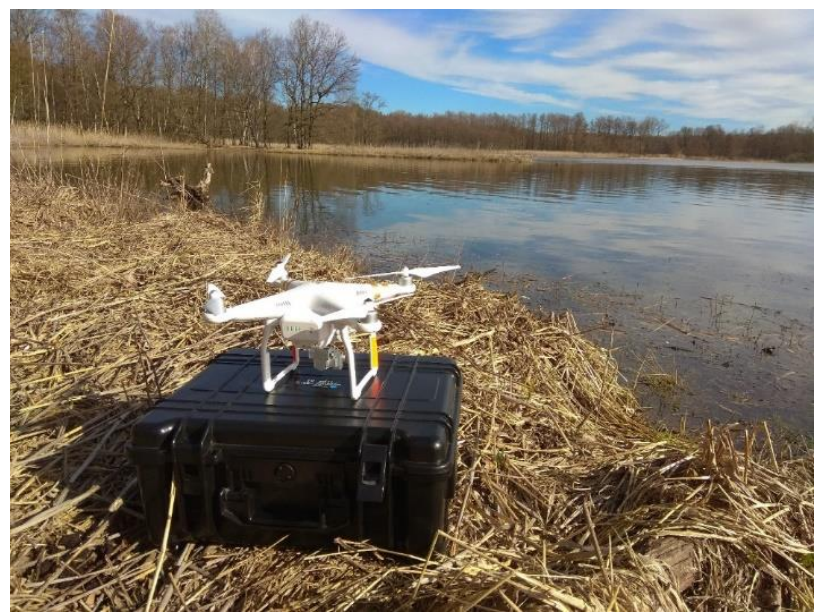

Figure 2. Phantom 3 on the shore of the area of interest (early April 2018).

\section{B. Flight Planning and Data Collection}

The case study is focused on utilization of a UAV for monitoring of the vicinity of small water bodies. Phantom 3 was used for monitoring (Fig. 2). Because of UAV utilization, there is no multi-spectral data available, so many indices used to detect landscape changes cannot be used. UAV is equipped with a DJI camera because no professional camera was available. A fast and cheap data collection with commonly available equipment is the main objective of this research.

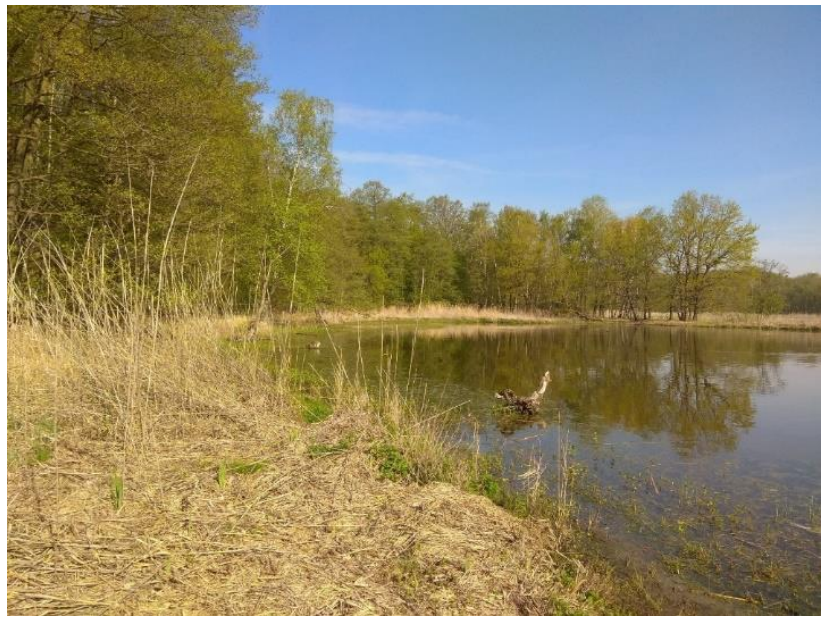

Figure 3. An image of the area of interest from the end of April 2018.

Data sets were taken in four-time horizons (February 9, 2018, March 8, 2018, April 5, 2018, April 20, 2018). The Phantom 3 has a mass of $1216 \mathrm{~g}, 4$ motors, a maximum climb speed of $5 \mathrm{~m} / \mathrm{s}$, a maximum descent speed of $3 \mathrm{~m} / \mathrm{s}$, a maximum speed of $16 \mathrm{~m} / \mathrm{s}$, max an available height of $6000 \mathrm{~m}$, a maximum range of $1000 \mathrm{~m}$ and a maximum flight time of about 25 minutes. Days were elected at almost a month's distance according to climatic conditions. The flight was scheduled in DJI GO and sent to the drones. Dron automatically flew as planned. Average speed was $2.2 \mathrm{~m} / \mathrm{s}$. Altitude was $39.6 \mathrm{~m}$. Data collection from the $0.0285 \mathrm{~km}$ area lasted approximately 15 minutes, so there was no need for a stop. Front and side overlaps were $60 \%$. 


\section{Data Processing}

Two software tools were used: OneButton 5.0 and ArcGIS for Desktop 10.5.1. OneButton was used to create a mosaic. WGS 84 - UTM Zone 33N was used as the coordinate system. ArcGIS was used for visual image interpretation, which was in the form of on-screen digitization. ArcGIS also has a final visualization of results, as this software provides sufficient tools for finalizing map outputs.

\section{Digitalization}

To analyze the change in the coastal zone at selected time horizons, it was important first to digitalize individual categories within all time horizons. Created mosaics for each time horizon (Fig. 4) were cropped in the same area. For the final analysis, a rectangular area of approximately $1905 \mathrm{~m}^{2}$ was used which includes only one coastal part (Fig. 5). The individual categories of the coastal zone were established at the beginning. The following categories were observed: water surface, ice, drawdown zone (periodically flooded areas), and coastal vegetation. Before digitization was necessary to create a polygon layer for each time horizon in ArcGIS. These layers were collected on-screen by digitizing the individual categories of the coastal zone. Created areas were subsequently added to the category ID. These ID numbers indicate the type of use of individual areas. The digitization process, of all time horizons, was very time-consuming. Fig. 6 shows the digitization result of the one-time horizon. The next step was to calculate the area of each area. This procedure has been applied to all time horizons. The final results were interpreted.
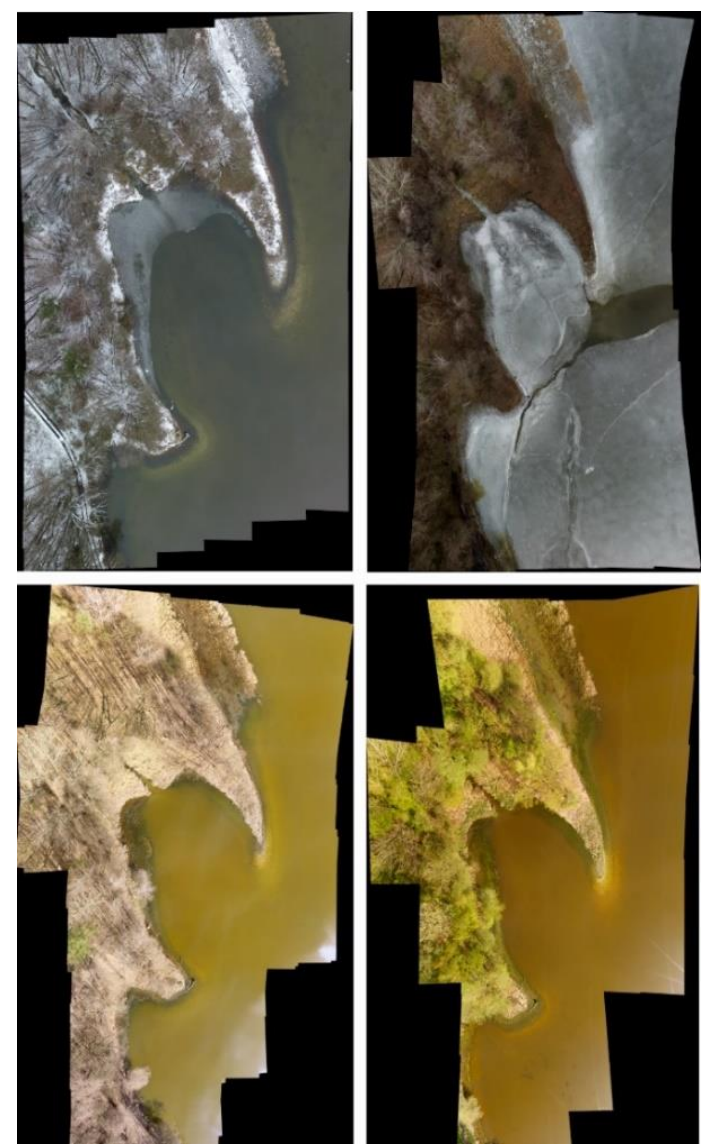

Figure 4. Mosaic images of monitored time horizons.
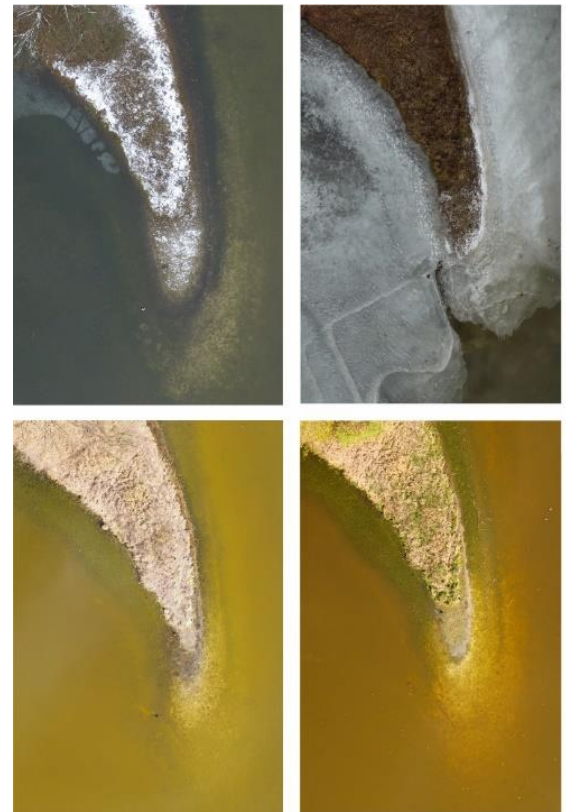

Figure 5. The final area of interest in individual time horizons

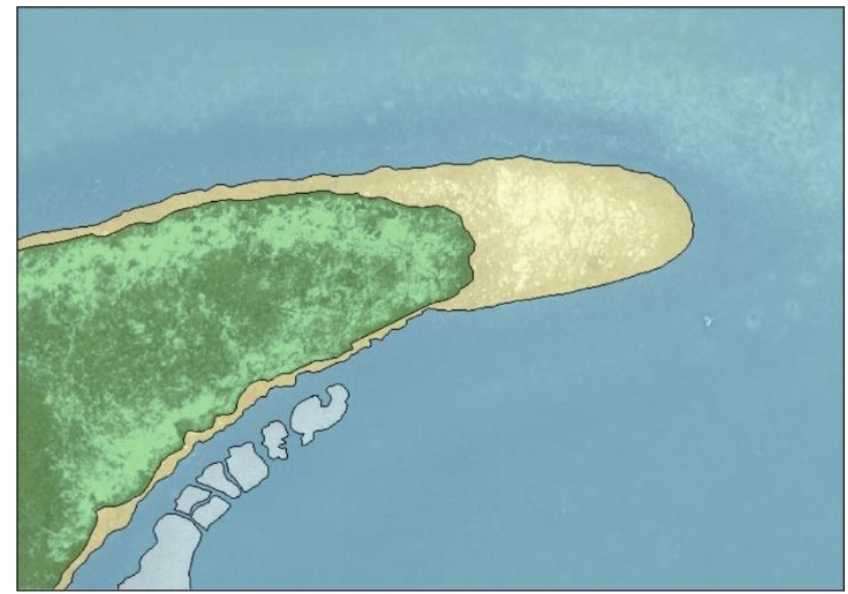

Figure 6. Example of digitalization of the February time horizon.

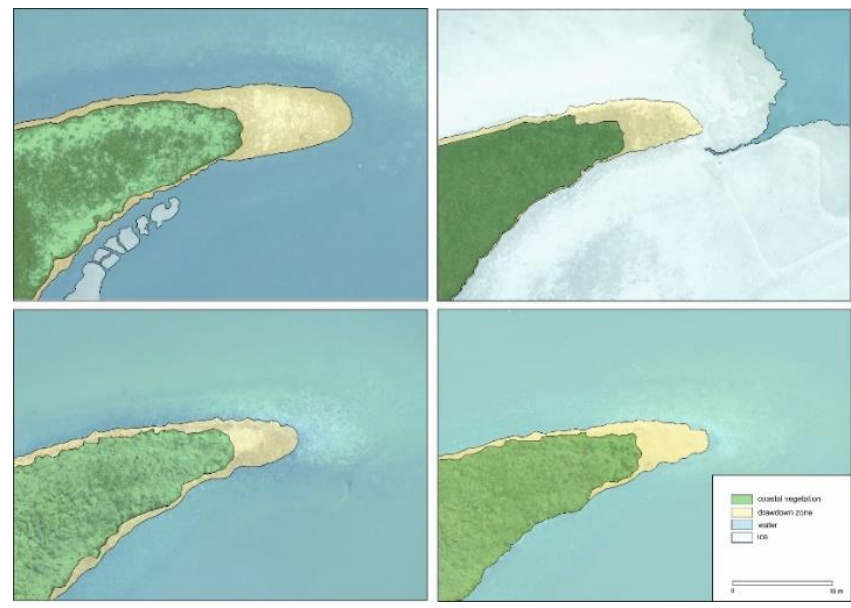

Figure 7. Final maps of one time horizons. 


\section{E. Interpretation of Results}

The resulting maps (Fig. 7) illustrate the changes in the coastal zone in the early months of 2018 . Tab. 1 shows the total category rating in individual time horizons in square meters. Tab. 1, Fig. 7, and Fig. 8 show that there were minimal changes at the beginning of the year. Images of February and March show ice on the water surface. The largest ice cover can be seen in the February picture. The largest area is reached by coastal vegetation in February. The smallest area occupies vegetation in March. The water surface occupies the largest area on the image from the end of April. In April 2018, the last remnants of snow and ice on the stream were heated and melted, which is also evidenced by the increased water level. New vegetation is well visible from the end of April. The smallest area occupies the water in the February picture when most of the surface is covered with ice. Each category was very well interpretable due to its high spatial resolution from the drones. Tracking the territory continued in the months to come. Changes in the amount of vegetation and loss of water in the tank as a result of dry summer months are also apparent in still unprocessed images that are not part of this study.

TABLE I. CHANGES IN THE Monitored CATEGoRIES IN INDIVIDUAL TIME HORIZONS

\begin{tabular}{|l|r|r|r|r|}
\hline $\begin{array}{l}\text { category / } \\
\text { month }\end{array}$ & February & March & $\begin{array}{r}\text { Beginning of } \\
\text { April }\end{array}$ & $\begin{array}{r}\text { End of } \\
\text { April }\end{array}$ \\
\hline $\begin{array}{l}\text { coastal } \\
\text { vegetation }\end{array}$ & 352.40 & 256.73 & 314.96 & 270.59 \\
\hline $\begin{array}{l}\text { drawdown } \\
\text { zone }\end{array}$ & 109.28 & 82.72 & 71.41 & 43.02 \\
\hline water & 1389.61 & 160.42 & 1508.45 & 1581.28 \\
\hline ice & 43.60 & 1395.07 & 0.00 & 0.00 \\
\hline
\end{tabular}

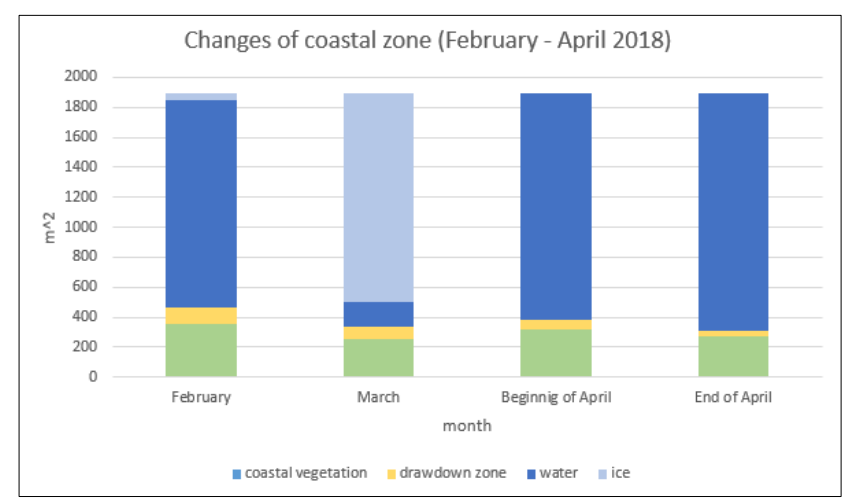

Figure 8. Changes in the monitored categories in individual time horizons.

\section{CONCLUSIONS}

The monitoring of landscape changes based on remote sensing data belongs to a long-developing field. With the growing need to focus on small water areas, the use of UAVs is also important. Drones enable flexible monitoring of small areas, of course, while respecting legislation and current meteorological conditions. They provide data with very high spatial resolution. Depending on the sensor, the data can be scanned either in visible spectral bands or in other bands. Even data captured only in visible spectral bands can be used to identify changes in the landscape, eg based on visual interpretation of individual time horizons. The article describes the collection, visualization, and interpretation of data from a low-cost UAV and demonstrates their excellent usability in monitoring changes in the vicinity of small water bodies.

\section{ACKNOWLEDGMENT}

The paper has been completed with the kind support of SGS project of Faculty of Economics and Administration, University of Pardubice number SGS_2019_17.

\section{REFERENCES}

[1] R. T. T Forman, and M. Godron, Landscape ecology. John Wiley and Sons, New York, New York, USA, 1986.

[2] E. H. Boak, and I. L. Turner, "Shoreline Definition and Detection: A Review, “Journal of Coastal Research, 21 (4), 2005, pp. 688-703.

[3] R. Dolan, et al., "The reliability of shoreline change measurements from aerial photographs," Shore and Beach, 48(4), 1980, pp. 22-29.

[4] J. H. List, and A. S. Farris, "Large-scale shoreline response to storms and fair weather, " Proceedings of the Coastal Sediments '99, 1999, pp. 13241337.

[5] R. A. Morton, "Accurate shoreline mapping: past, present, and future, “ Proceedings of the Coastal Sediments '91, 1991, pp. 997-1010.

[6] G. L. Smith, and G. A. Zarillo, "Calculating long-term shoreline recession rates using aerial photographic and beach profiling techniques, “ Journal of Coastal Research, 6(1), 1990, pp. 111-120.

[7] J. Komarkova, and P. Sedlak, "UAV Spectral Image Mapping of Shoreline Vegetation", GIM INTERNATIONAL-THE WORLDWIDE MAGAZINE FOR GEOMATICS, vol. 32, no. 6, 2018, pp. 26-27,

[8] D. Gorkovchuk, J. Gorkovchuk, and B. Hutnyk, "Photogrammetry for Mining: Exploring Consumer-grade Copters for Quarry Mapping”. [online]. 19.10.2017 [cit. 2019-02-13]. Available: https://www.gim-international.com/content/article/low-cost-uasphotogrammetry-for-

mining?utm_source=Newsletter+Superlist\&utm_campaign=5afc1de9b6EMAIL_CAMPAIGN_2017_10_19GIM\&utm_medium=email\&utm_ter $\mathrm{m}=0$ 0_9bcc6040d6-5afc1de9b6-46151793

[9] D. Martínez, A. Sarabia, and S. García, "UAS in Farming: A Pilot Project in Cuba". [online]. 23/04/2014 [cit. 2019-02-13]. Available: https://www.gim-international.com/content/article/uas-in-farming

[10] G. Tumlisan, K. Bronsveld, and M. Koeva, "UAS-based Measurement of Crop Height and Biomass: Monitoring Crop Growth and Estimating Yield Production in Precision Farming". [online]. 24/01/2018 [cit. 2019-02-13]. Available: https://www.gim-international.com/content/article/uas-basedmeasurement-of-crop-height-and-

biomass?utm_source $=$ Newsletter + Superlist\&utm_campaign $=4 \mathrm{~b} 43 \mathrm{~b} 3 \mathrm{~d} 34$ 0

EMAIL_CAMPAIGN_2018_01_25GIM\&utm_medium=email\&utm_ter $\mathrm{m}=0$ 9bcc6040d6-4b43b3d340$46151793 \&$ mc_cid $=4 b 43 b 3 d 340 \& m c \_$eid $=8 \mathrm{e} 06 \mathrm{fb} 45 \mathrm{f} 3$

[11] J. Karas, "UAS and Flooding: Monitoring Flooding and Assessing Damage in the Czech Republic". [online]. 02/12/2013 [cit. 2019-02-13]. Available: https://www.gim-international.com/content/article/uas-andflooding

[12] S. Amici and M. Turci, "Monitoring Vulcanoes with UAS: Testing the Suitability of Thermal Infrared Sensors". [online]. 06/06/2014 [cit. 201902-13]. Available: https://www.giminternational.com/content/article/monitoring-vulcanoes-with-uas

[13] K. Whitehead, "Unmanned Aerial Vehicles for Glaciological Studies: Airborne Survey of Fountain Glacier's Terminus Region”. [online]. 04/10/2010 [cit. 2019-02-13]. Available: https://www.giminternational.com/content/article/unmanned-aerial-vehicles-forglaciological-studies

[14] J. Karas and V. Šafár̆, "UAS Photogrammetry and Railway Mapping: Pilot in the Czech Republic Attains High-precision Results". [online]. 29/03/2017 [cit. 2019-02-13]. Available: https://www.giminternational.com/content/article/uas-photogrammetry-and-railwaymapping 